\title{
KONSELING ALKITABIAH LUKA BATIN DAN RELEVANSINYA DENGAN MINAT BELAJAR ANAK-ANAK SEKOLAH MENENGAH TEOLOGI KRISTEN (SMTK) WAIKABUBAK SUMBA BARAT
}

\author{
Tonny Andrian \\ Sekolah Tinggi Teologi Kharisma Bandung \\ ta.restoration153@gmail.com
}

Diterima:

28-12-2020

Direview:

30-01-2021

15-03-2021

Direvisi:

06-02-2021

22-03-2021

Diterbitkan:

30-04-2021

Keywords:

biblical

counseling, inner wounds, learning interest, SMTK

Waikabubak

Sumba Barat

Kata Kunci: konseling alkitabiah, luka batin, minat belajar, SMTK Waikabubak Sumba Barat

\section{Abstract}

By carrying out the activities of the lecturers through community service, in carrying out Biblical counseling teaching and training, it will improve the teacher's ability to develop counseling for children who are hurt mentally This is proven when a teacher provides a biblical understanding of counseling, it will certainly affect learning and increase the motivation for children's interest in learning. The writing method for reporting the implementation of biblical counseling for the inner wounds of the children of the Waikabubak West Sumba Christian Theology Middle School (SMTK) with an interest in learning children is through training, teaching and seminars. This activity took place in stages in 2014, 2015 and 2017. The results achieved from this implementation activity were the increasing quality of the Spirituality, Mentality and Intellectuality of the Sumba Church Community, especially the Waikabubak Christian Theological High School, West Sumba.

\section{Abstrak}

Dengan melakukan kegiatan para dosen melalui pengabdian kepada masyarakat ini, dalam melaksanakan pengajaran dan pelatihan konseling alkitabiah, akan meningkatkan kemampuan guru dalam mengembangkan konseling terhadap anak-anak yang terluka batinnya. Hal ini dibuktikan ketika seorang guru memberikan pemahaman konseling berdasarkan Alkitab, maka dipastikan akan berpengaruh terhadap pembelajaran dan meningkatkan motivasi minat belajar anak. Metode penulisan pelaporan pelaksanaan konseling Alkitabiah luka batin anak-anak Sekolah Menengah Teologi Kristen (SMTK) Waikabubak Sumba Barat dengan minat belajar Anak ini adalah melalui pelatihan, pengajaran dan Seminar. Adapun kegiatan ini berlangsung secara bertahap di tahun 2014, 2015, dan 2017. Hasil yang dicapai dari kegiatan pelaksanaan ini adalah semakin meningkatnya Mutu Spiritualitas, Mentalitas, dan 
Intelektualitas Masyarakat Gereja Sumba khususnya Sekolah Menengah Atas Teologi Kristen Waikabubak Sumba Barat.

\section{Pendahuluan}

Pendidikan merupakan salah satu faktor penting dalam pembangunan ekonomi karena berperan membentuk kemampuan sebuah negara untuk menyerap teknologi dan mengembangkan kapasitas. Tujuan dari penelitian melalui PkM ini adalah untuk mengetahui gambaran pengetahuan remaja dan sikap remaja Sekolah Menengah Teologi Kristen (SMTK) Waikabubak Sumba Barat yang putus sekolah disebabkan salah satu faktornya adalah luka batin yang penyebabnya adalah kekerasan dalam rumah tangga. Penelitian yang dilakukan oleh Sudarwati yang menyimpulkan bahwa pendidikan KDRT ditemukan sebagai faktor keluarga yang berpengaruh terhadap kelulusan dan putus sekolah. ${ }^{1}$ Orangtua dengan tingkat KDRT yang lebih tinggi tidak mampu memberikan dorongan kepada anaknya untuk melanjutkan sekolah ke jenjang pendidikan yang lebih tinggi. Berdasarkan hasil penelitian Zulkarnain, ${ }^{2}$ jumlah anak yang semakin banyak luka batin disebabkan banyak keluarga yang melakukan KDRT. Keluarga melakukan KDRT disebabkan sulitnya memenuhi kebutuhan pokok keluarga dan juga kebutuhan pendidikan anak- anaknya sampai ke jenjang pendidikan. Arizona, ${ }^{3}$ dalam penelitiannya menyimpulkan bahwa keluarga dengan tingkat ekonomi rendah secara otomatis akan mengorbankan anak-anaknya untuk turut bekerja menambah penghasilan keluarga sehingga anak-anak usia sekolah akan putus sekolah untuk bekerja dan membantu perekonomian keluarga. ${ }^{4}$

Salah satu sekolah Menengah Teologi Kristen SMTK Waikabubak Sumba Barat yang sedang berbenah satu-satunya di Jl. Posal Kanatang - Waikabubak Sumba Barat Sekolah tersebut sebenarnya adalah perintisan dari pelayanan serta dukungan dari Bapak Dr. Tonny Andrian. Tanpa ada kegiatan lanjutan dan dukungan dari program Sekolah Tinggi Menengah Teologi Kristen SMTK Waikabubak Sumba Barat tidak akan berdiri. Salah satu guru menyebutkan bahwa semua guru yang mengajar pada sekolah tersebut hampir tidak pernah diikutkan pelatihan terkait pengembangan pembelajaran terutama Konseling alkitabiah terhadap anak-anak yang terluka akibat KRT, sehingga pengetahuan mereka hanya terbatas pada bagaimana menyampaikan materi yang ada di buku teks. Tanpa melihat ada luka batin anak-anak sekolah yang menyebabkan minat belajar mereka

\footnotetext{
${ }^{1}$ Sudarwati. (2009). Perbedaan Resiko Putus Sekolah Anak Usia 7-15 Tahun pada tahun 1998 dan 2006 di Indonesia. Tesis Universitas Indonesia. Jakarta.,h.56

${ }^{2}$ Zulkarnain, Ajis, O.T., \& Sugiyanta, I.G. (2013). Faktor-Faktor Penyebab Anak Putus Sekolah pada Tingkat SMA di Kelurahan Gedong Meneng Kecamatan Rajabasa Kota Bandar Lampung Tahun 2012. Jurnal Penelitian Geografi 1 (3).

${ }^{3}$ Arizona,M.M.(2013).KajianTentangSiswaPutusSekolahPadaTingkatSMA/SMKDiKabupatenGresik(Stu di Kasus Di Kecamatan Gresik Kabupaten Gresik). Swara Bhumi e-Journal Pendidikan Geografi FIS Unesa, 2(3), 151-158.

${ }^{4}$ Ibid
} 
menurun. Selain itu permasalahan lainnya adalah pergaulan anak anak yang cenderung bebas. Dampak dari ini semua siswa yang ada di sekolah ini kurang termotivasi dalam belajar sehingga banyak siswa yang ada di sekolah ini terkesan ogah-ogahan dalam belajar. ${ }^{5}$ Lokasi Jl. Posal Kanatang - Waikabubak Sumba Barat, Sekolah yang sulit untuk dijangkau dan pandangan masyarakat kesukuan yang masih primitif-Animisme membuat sebagian suku pedalaman di Pulau Sumba Barat seolah terisolasi dari kehidupan modern masyarakat baik secara materi, Spritualitas, Mentalitas, dan Intelektualitas. Namun sayangnya di balik keindahan dan kekayaan Wisatanya, masih ada sebagian besar masyarakat kurang memahami Pendidikan Konseling. Melalui pendidikan konseling, anakanak mudah untuk membuat keputusan yang terkait dengan masalah kesehatan seksual mereka dan diajarkan menjadi pribadi yang bertanggung jawab. Penelitian PkM ini dilakukan untuk mengetahui gambaran pengetahuan remaja dan sikap remaja tentang pendidikan konseling pada remaja kelas XI di SMTK Waikabubak Sumba Barat.

TabelPersentase anak usia SMTK di Sumba Barat menurut status bersekolah dan pendidikan KRT, 2017.

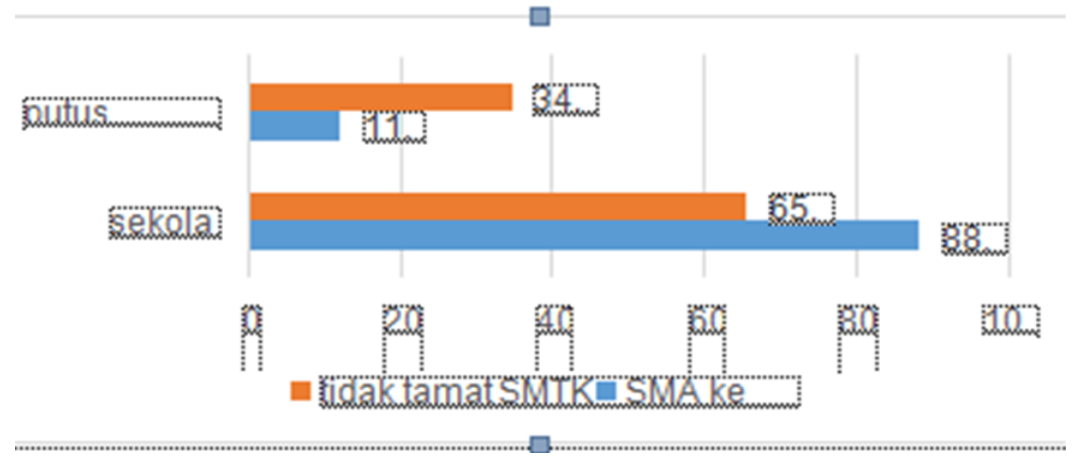

Berdasarkan hasil wawancara dan observasi terhadap beberapa guru yang ada di sini terdapat beberapa masalah yang dihadapi oleh guru-guru yang ada di sekolah ini yaitu kurangnya kegiatan pelatihan pembelajaran konseling secara alkitabiah. Setelah ditelusuri lebih jauh masalah yang ada dalam Sekolah Menengah Teologi Kristen ini adalah yaitu kurangnya pengetahuan secara alkitabiah, sehingga penelitian yang ditemukan oleh Dr. tonny Andrian (2017) bahwa jumlah anak sekolah yang semakin meningkat setiap tahun ternyata masih mengalami berbagai masalah serius baik masalah dalam input maupun proses outputnya. Adapun manfaat yang diharapkan dari kegiatan pengabdian pada masyarakat ini adalah meningkatkan tanggung jawab profesionalisme dosen melalui pengabdian masyarakat. Terjalinnya kerjasama secara berkelanjutan antara Sekolah Kharisma Bandung dengan sekolah menengah Teologi Kristen Waikabubak Sumba Barat serta meningkatnya pengetahuan dan pemahaman akan aspek pengembangan bahan ajar. Selain itu meningkatnya daya saing sekolah meningkatnya kualitas minat belajar anak.

${ }^{5}$ SUSENAS, BPS 2016 (diolah) 
$\underline{\text { Jurnal PkM Setiadharma|Volume 2, Nomor 1, April } 2021}$

\section{METODE KEGIATAN}

Metode pelaksanaan Pengabdian melibatkan masyarakat kristiani Pulau Sumba setempat dan mereka (para pengerja, pemimpin, guru-guru) yang sudah ikut seminar sebelumnya. Adapun Metode kegiatan terdiri dari Model-Model pembelajaran satu dengan yang lainnya.

1. Metode Seminar

Seminar ini selalu disertai penayangan gambar animasi atau film video singkat Pendukung atas materi tersebut bahkan ada diskusi kelompok, agar semua materi dapat diterima dengan baik oleh mereka semua.

2. Workshop

Metode ini digunakan untuk memberikan tugas kepada para peserta untuk mempraktikkan bagaimana cara melatih kemampuan Spritualitas, Mentalitas, dan Intelektualitas sesuai dengan Perspektif Alkitab.

\section{PEMBAHASAN DAN HASIL}

Luka batin dapat ditimbulkan oleh banyak penyebab. Berdasarkan hasil pelaksanaan PkM di Sekolah Menengah Teologi Kristen (SMTK) Waikabubak Sumba Barat, penyebab dari luka batin yang dialami oleh siswa yang ada di sana adalah sebagai berikut:

\section{Pelecehan (Abuse)}

Luka batin bisa ditimbulkan karena adanya pelecehan yang dialami oleh seseorang yang umumnya pada masa kecil. Ada beberapa jenis pelecehan yang bisa menyebabkan luka batin:

\section{Physical Abuse}

Pelecehan secara fisik terjadi apabila orangtua melakukan tindakan disiplin fisik kepada anaknya secara berlebihan dan tidak manusiawi. Akibatnya hal itu akan menimbulkan kebencian dan kemarahan di dalam diri anak tersebut yang akan terus dibawa dalam perkembangan hidupnya. Oleh sebab itu orangtua harus berhati-hati dalam mendisiplin anak-anaknya. Orangtua boleh menghajar anaknya yang nakal tapi jangan menginginkan kematiannya baik secara fisik maupun psikis (Ams. 19:18).

\section{Masalah Keluarga}

Luka batin yang dimiliki seseorang akan mempengaruhi kehidupan suami-istri di dalam keluarga yang dibentuknya. Ada banyak masalah-masalah keluarga yang muncul sebagai akibat dari adanya luka batin yang dimiliki oleh istri atau suami dalam sebuah keluarga tersebut. Adapun masalah-masalah yang muncul di antaranya:

\section{a. Tidak Mampu Berkomunikasi}


Seseorang yang mengalami luka batin akan sulit untuk bisa memiliki komunikasi yang baik dan sehat di dalam hubungan suami-istri. Ia mungkin bisa berkomunikasi tetapi dengan cara yang salah. Ia akan memakai cara-cara berkomunikasi seperti yang dilakukan oleh orangtuanya terhadap dirinya dimasa lalu. Ia berkomunikasi dengan gaya bahasa yang kasar, kotor, menghakimi dan menyakiti pasangannya. Hal ini akan menimbulkan pertengkaran dan percekcokan di dalam keluarga. Sebagai akibatnya maka suami-istri tidak akan berbicara satu dengan yang lainnya.

\section{b. Status Pendapatan}

Dari hasil analisis PkM yang telah dilakukan, diketahui bahwa status pendapatan rumah tangga berpengaruh signifikan terhadap putus sekolah. Dari hasil PkM diperoleh nilai ratio untuk status pendapatan rumah tangga adalah sebesar 1,805. Hal ini berarti putus sekolah cukup besar dibandingkan dengan anak yang berada dalam rumah tangga dengan status pendapatan tinggi. Jumlah Anak dalam Rumah Tangga. ${ }^{6}$

\section{c. Masalah KDRT}

Luka batin yang dialami seseorang, khususnya anak-anak Sekolah Menengah Teologi Kristen (SMTK) Waikabubak Sumba Barat yang disebabkan oleh adanya KDRT dalam keluarga. Hal ini dapat mengganggu kehidupan dalam masa belajar siswa Sekolah Menengah Teologi Kristen (SMTK) Waikabubak Sumba Barat. Hal ini juga akan menimbulkan trauma masa lalu terus membayangi kehidupan siswa-siswi SMTK Sumba Barat.

Sebagai akibatnya siswa SMTK Sumba Barat akan terganggu proses belajar mengajar (PBM). Pada akhirnya menyebabkan menurunnya minat belajar siswa SMTK Sumba Barat. Apabila hal ini tidak segera diatasi maka akan membawa dampak yang lebih buruk yaitu banyaknya siswa yang putus sekolah. Kalau hal ini terjadi maka kehancuran masa depan anak-anak tinggal menunggu waktu saja. Konflik, ketidakpercayaan, kebencian, dan kemarahan akan menguasai kehidupan siswa SMTK Sumba Barat tersebut. Akhirnya mereka mengalami luka batin dan akan menjadi alternatif untuk putus dari sekolah.

Dari uraian di atas dapatlah dikatakan luka batin yang dialami seseorang (khusunya di SMTK Sumba Barat) sungguh sangat berbahaya bagi hidup dan kehidupan mereka. Oleh sebab itu luka batin harus segera dipulihkah agar tidak terus menggerogoti hidup dan kehidupan seseorang.

Pemulihan luka batin juga perlu agar pengalaman luka batin tidak terulang lagi di dalam hidup anak-cucu seseorang yang mengalami luka batin. Seseorang yang mengalami pengalaman pahit masa lalu yang menimbulkan luka batin akan memperlakukan anaknya secara sama dengan apa yang perlu dilakukan orangtuanya kepadanya. Akibatnya anak pun akan mengalami luka batin. Hal ini akan terulang dan terulang lagi di dalam generasi berikutnya. Oleh karena itu luka batin tidak boleh dibiarkan tapi harus segera disembuhkan.

Berdasarkan pembahasan dan hasil, dapat disimpulkan bahwa proporsi anak usia SMTK yang putus sekolah di Waikabubak Sumba Barat tahun 2017 masih relatif besar. Anak usia SMTK yang berjenis kelamin laki-laki dan tinggal di pedesaan memiliki peluang yang lebih besar untuk mengalami putus sekolah. Begitu juga mereka yang berasal dari rumah tangga berpendapatan rendah dan jumlah anak dalam rumah tangga lebih dari 2 orang. Hal yang sama juga berlaku untuk mereka yang berasal dari rumah tangga dengan KDRT bekerja di sektor pertanian dan berpendidikan tidak tamat SMA. 
Kegiatan PkM yang dilaksanakan dengan acara tatap muka Penerapan Pembaruan Alkitab. Dalam Peningkatan Mutu Spiritualitas, Mentalitas dan Intelektualitas Masyarakat Gereja Sumba Barat untuk peningkatan terhadap para jemaat dan pengerja gereja dan masyarakat gerejawi, khususnya di Pulau Sumba Barat kemampuan setiap masyarakat gerejawi Sumba. Suatu pemikiran tepat agar masyarakat gerejawi Sumba Barat mengalami kemajuan secara pribadi dan berdampak pembaruan bagi masyarakat sekitar. Pertemuan tatap muka dengan metode ceramah dan demonstrasi, dilanjutkan tanya jawab.

Kegiatan ini dilaksanakan sehari yaitu pada Desember 2017 dari pukul $10.00-17.00$ WIB. Peserta kegiatan berjumlah 500 orang jemaat dan 100 pengerja gereja. Lokasi penyelenggaraan di lapangan terbuka Balai Desa. Pelaksanaan kegiatan PkM ini dilakukan oleh 1 (satu) orang tim pengabdi dari Sekolah Tinggi Teologi Kharisma Bandung, dengan pokok bahasan yang disampaikan mengenai:

1. Mengapa kita perlu pembaharuan dan apa itu pembaharuan?

2. Bagaimana menerapkan konsep pembaharuan ini dalam kehidupan sehari-hari?

3. Apakah berguna untuk hidup bagi masyarakat sekitar?

Sangat terlihat masyarakat gerejawi belum mampu merespon atas potensi dari daerah mereka sendiri khususnya dengan segala keterbatasan spiritualitas, mentalitas, intelektualitas. Acara ini juga dilanjutkan dengan sesi Tanya jawab yang berkonsentrasi atas pembaharuan alkitabiah tersebut.

Hasil kegiatan PkM secara garis besar mencakup target peserta seminar seperti yang direncanakan sebelumnya adalah paling tidak dihadiri 100 orang jemaat dan pengerja gereja, sesuai dengan jumlah materi yang disediakan sebelumnya. Dengan demikian dapat dikatakan bahwa target peserta tercapai dan malampaui angka 100\%. Angka tersebut menunjukkan bahwa kegiatan PkM dilihat dari jumlah peserta yang mengikuti dapat dikatakan berhasil/sukses. Ketercapaian tujuan penerapan Pembaharuan Alkitab dalam peningkatan Mutu Spiritualitas, Mentalitas dan Intelektualitas. Kemampuan peserta dilihat dari penguasaan materi masih kurang dikarenakan waktu yang singkat dalam penyampaian materi dan kemampuan para peserta yang berbeda-beda. Hal ini disebabkan jumlah materi yang banyak hanya disampaikan dalam waktu sehari sehingga tidak cukup waktu bagi para peserta untuk memahami dan mempraktekkan secara lengkap semua materi yang diberikan. Secara keseluruhan penerapan Pembaharuan Alkitab dalam peningkatan Mutu Spritualitas, Mentalitas dan Intelektualitas. Sesi ke-Satu ini baik dalam arti kata masyarakat Sumba mengerti tentang makna Pembaruan alkitabiah dan bisa dimanfaatkan dalam kehidupan sehari-hari terasa sekali antuasiasnya dengan permohonan mereka kepada kami untuk kembali melanjutkan pengabdian Masyarakat ini dengan Tema yaitu "Penerapan Pembaruan alkitabiah"

Pada kegiatan konseling alkitabiah, setiap kelompok menyediakan materi, media dan penilaian berdasarkan RPP yang telah dibuat. Setelah itu salah satu perwakilan dari setiap 
kelompok berperan sebagai guru dan anggota kelompok yang lainnya akan menjadi observer dan siswa.

Setelah salah satu kelompok melakukan presentasi, kelompok tersebut kemudian mempresentasikan hasil observasi dari kegiatan konseling alkitabiah tersebut, para peserta dominan mengakui bahwa melalui kegiatan seperti ini mereka bisa mengetahui cara masing-masing guru mengajar dikelas. Meskipun selama ini mereka adalah teman sejawat namun tidak pernah melihat secara langsung bagaimana kolega mereka mengajar.Pelatihan Konseling alkitabiah ini dapat meningkatkan kemampuan mengajar guru terhadap minat belajar anak. Hal ini sejalan dengan hasil penelitian dari Ogegbo, Estelle \& Trisha yang menemukan bahwa kolaborasi melalui Konseling alkitabiah meningkatkan minat belajar anak dengan strategi pengajaran gruru professional, kemampuan membangun jarigan, menyusun RPP, manajemen kelas, dan perilaku positif dalam mengajar.Kegiatan PKM ini diakhir dengan pemberian form refleksi kepada setiap peserta. Hal ini dilakukan untuk mengetahui manfaat dan kekurangan dari kegiatan yang dilakukan. ${ }^{7}$

\section{KESIMPULAN}

Program pendampingan informasi ini dapat di selenggarakan dengan baik dan berjalan dengan lancar sesuai dengan kegiatan yang telah di susun. Kegiatan ini mendapat sambutan sangat baik terbukti dengan keaktifan peserta mengikuti pendampingan dengan tidak meninggalkan tempat sebelum seminar konseling berakhir. Berdasarkan hasil evaluasi pelaksanaan PkM ada 3 anak dari Sekolah Menengah Teologi Kristen (SMTK) Waikabubak Sumba Barat yang pada akhirnya setelah tamat mereka mau masuk sekolah Alkitab Tiranus. Sejak diadakan pelaksanaan Konseling alkitabiah luka batin dan relevansinya minat belajar di SMTK Sumba Barat semakin membaik. Oleh sebab itu dari hasil PkM maka dapat diajukan beberapa saran sebagai berikut:

1. Waktu pelaksanaan kegiatan pengabdian perlu di tambah agar tujuan kegiatan dapat tercapai sepenuhnya, tetapi dengan konsekuensi penambahan biaya pelaksanaan, mengingat Khalayak sasaran yang berbeda pula.

2. Adanya kegiatan lanjutan yang berupa pelatihan sejenis selalu diselenggarakan secara periodik sehingga dapat meningkatkan kemampuan jemaat dan Pengerja Gereja yang ada di daerah-daerah, khususnya di Pulau Sumba Barat dalam melaksanakan pelayanan mereka yang menghadapi KRT dan terputusnya anakanak sekolah dalam melaksanakan pendidikan.

\footnotetext{
${ }^{7}$ Ogegbo, Ayodele Abosede; Gaigher, Estelle;Salagaram, Trisha . (2019) . Benefits and Challenges of Lesson Study: A Case of Teaching Physical Sciences in South Africa. South African Journal ofEducation, v39 n1 Article 1680.https://eric.ed.gov/?q=lesson+study\&id=EJ1210353
} 

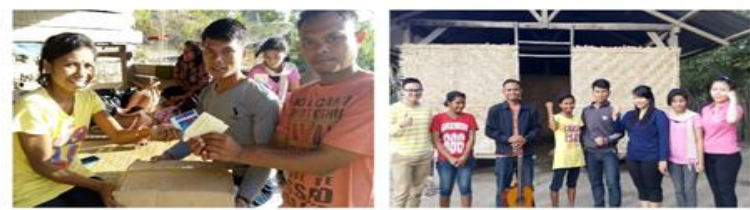

Pengabdian

Masyarakat

Yang dilakukan

Dengan cara aktivitas

Pembagian sembako

Yang melatih para mahasiswa
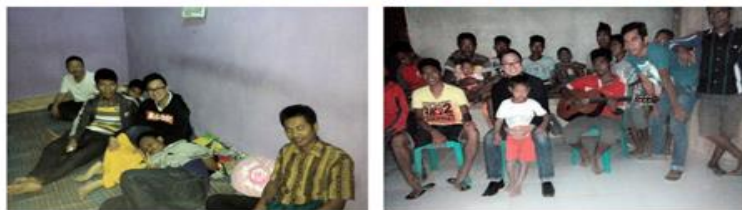

mahasiwi STT

DAN KONSELING

ALKITABIAH

BAGI PARA ANAK MELALUI

PENGAJARAN PENGAJARAN

YANG BERSIFAT

MEMBAHARUKAN
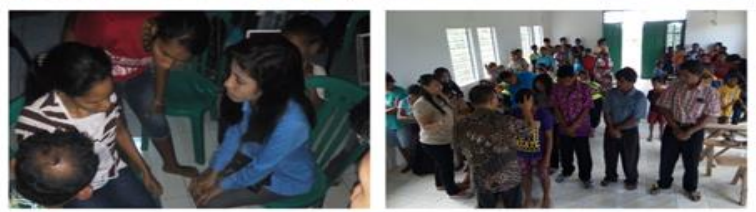

MENTALITAS,SPIRITUALITAS

INTELEKTUALITAS PARA

PESERTA

DIDIK TERSEBUT

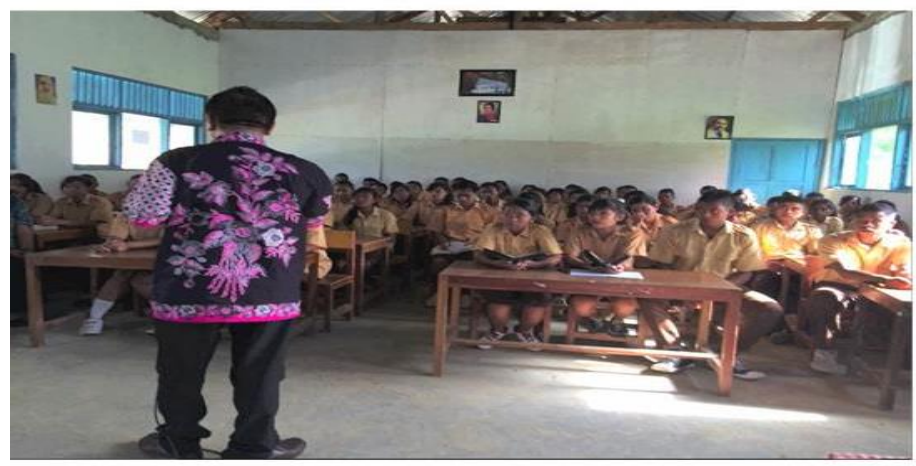

Pelayanan

DI SMTK

WAIKABUBAK 2014

SEMINAR TENTANG

INJIL ADALAH

KEKUATAN

TUHAN

Setelah seminar langsung Kita mengadakan ibadah Sebagai suatu upaya untuk mengetahui Kondisi spiritualitas dari para siswa SMTK WAIKABUBAK

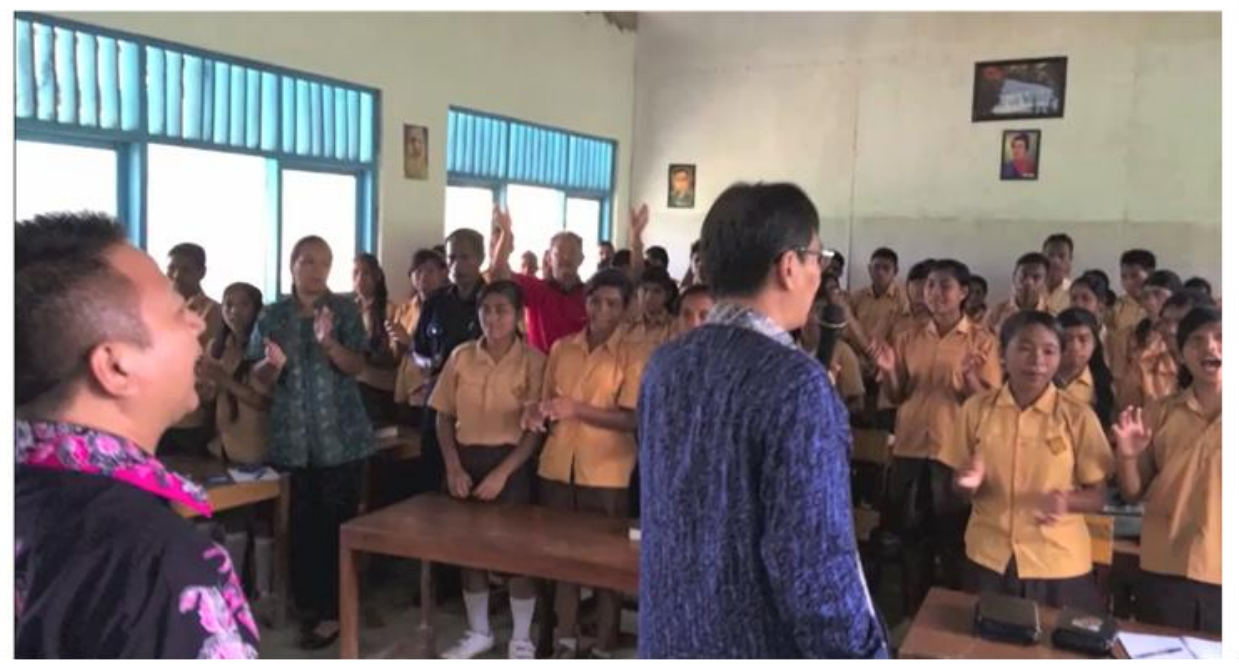




\section{DAFTAR PUSTAKA}

Arizona,M.M.(2013).KajianTentangSiswaPutusSekolahPadaTingkatSMA/SMKDiKabupa tenGresik(Studi Kasus Di Kecamatan Gresik Kabupaten Gresik). Swara Bhumi eJournal Pendidikan Geografi FIS Unesa, 2(3),151-158.

SUSENAS, BPS 2016 (diolah)

Nyoman Sudana Degeng dan I Putu Ayub Darmawan, "Peningkatan Profesionalisme Pendidik Melalui Penelitian dan Penulisan Karya Ilmiah," dalam Prosiding Seminar Nasional Pendidikan Agama Kristen dan call for papers (Seminar Nasional Pendidikan Agama Kristen dan call for papers., Ungaran: Sekolah Tinggi Teologi Simpson, 2017), http://semnas.sttsimpson.ac.id/index.php/SNPK/article/view/16.

Djama. 2010, Analisis Sikap Seksualitas Remaja Siswa SMA di Kota Waingapu Kabupaten Sumba Timur. Diunduh pada tanggal 23 Desember 2015

Dewey, John. 1958. Philosophy of Education, Ames, lowa: Uttlefield, Adams \& Co,h.26

Astley, Jeff. 1994. The Philosophy of Christian Education. Birmingham, Alabama: Religious Education Press

Sudarwati. (2009). Perbedaan Resiko Putus Sekolah Anak Usia 7-15 Tahun pada tahun 1998 dan 2006 di Indonesia. Tesis Universitas Indonesia. Jakarta.,h.56

Zulkarnain, Ajis, 0.T., \& Sugiyanta, I.G. (2013). Faktor-Faktor Penyebab Anak Putus Sekolah pada Tingkat SMA di Kelurahan Gedong Meneng Kecamatan Rajabasa Kota Bandar Lampung Tahun 2012. Jurnal Penelitian Geografi 1 (3).

Lestari, R \& Afifah, N. (2017). Penerapan Lesson Study untuk Meningkatkan Kemampuan Dasar Mengajar Https://ejournal.unri.ac.id/index.php/IBT/

Ogegbo, Ayodele Abosede; Gaigher, Estelle;Salagaram, Trisha . (2019) . Benefits and Challenges of Lesson Study: A Case of Teaching Physical Sciences in South Africa. South African Journal ofEducation, v39 n1 Article 1680.https://eric.ed.gov/?q=lesson+study\&id=EJ1210353

Putra, R. S., Wijayati, N., \& Widhi, F. (2009).

Pengaruh Penggunaan Media

Pembelajaran berbasis Aplikasi Android terhadap Hasil Belajar Siswa.

Rizki Suhendar Putra, Nanik Wijayati, F. Widhi Mahatmanti. (2017). Pengaruh Penggunaan Media Pembelajaran Berbasis Aplikasi Android terhadap Hasil Belajar Siswa. Journal Unnes. Vol 11 , No 2.https://journal.unnes.ac.id/nju/index.php/IIPK/article/view/10628 